\title{
SOME PROPERTIES FOR A CLASS OF SYMMETRIC FUNCTIONS AND APPLICATIONS
}

\section{Yu-Ming Chu, Wei-Feng Xia And Tie-Hong Zhao}

Abstract. For $x=\left(x_{1}, x_{2}, \cdots, x_{n}\right) \in \mathbb{R}_{+}^{n}$, the symmetric function $F_{n}(x, r)$ is defined by

$$
F_{n}(x, r)=F_{n}\left(x_{1}, x_{2}, \cdots, x_{n} ; r\right)=\prod_{1 \leqslant i_{1}<i_{2} \cdots<i_{r} \leqslant n} \frac{\sum_{j=1}^{r} x_{i_{j}}}{\sum_{j=1}^{r}\left(1+x_{i_{j}}\right)},
$$

where $r=1,2, \cdots, n$ and $i_{1}, i_{2}, \cdots, i_{n}$ are positive integers. In this article, the Schur convexity, Schur harmonic convexity and Schur multiplicative convexity of $F_{n}(x, r)$ are discussed. As applications, some inequalities are established by use of the theory of majorization.

Mathematics subject classification (2010): 05E05, 26B25.

Keywords and phrases: Symmetric function, Schur convex, Schur harmonic convex, Schur multiplicatively convex, theory of majorization.

\section{REFERENCES}

[1] T. Hara, M. Uchiyama, S. TAKahasi, A refinement of various mean inequalities, J. Inequal. Appl., 2 (1998), 387-395.

[2] H. T. KU, M. C. KU, X. M. ZHANG, Inequalities for symmetric means, symmetric harmonic means, and their applications, Bull. Austral. Math. Soc., 56 (1997), 409-420.

[3] P. S. Bullen, Handbook of Means and Their Inequalities, Kluwer Academic Publishers Group, Dordrecht, 2003.

[4] K. Z. GuAn, The Hamy symmetric function and its generalization, Math. Inequal. Appl., 9 (2006), 797-805.

[5] A. W. Marshall, I. Olkin, Inequalities: Theorey of Majorization and Its Applications, Academic Press, New York, 1979.

[6] G. H. Hardy, J. E. Littlewood, G. Pólya, Some simple inequalities satisfied by convex functions, Messenger Math., 58 (1929), 145-152.

[7] Y. M. Chu, X. M. Zhang, G. D. WAng, The Schur geometrical convexity of the extended mean values, J. Convex Anal., 15 (2008), 707-718.

[8] K. Z. GUAN, A class of symmetric functions for multiplicatively convex function, Math. Inequal. Appl., 10 (2007), 745-753.

[9] Y. M. CHU, Y. P. LV, The Schur harmonic convexity of the Hamy symmetric function and its applications, J. Inequal. Appl., 2009 (2009), Art. ID 838529, 10pp.

[10] K. Z. GuAN, Schur-convexity of the complete symmetric function, Math. Inequal. Appl., 9 (2006), $567-576$.

[11] S. H. WU, Generalization and sharpness of the power means inequality and their applications, J. Math. Anal. Appl., 312 (2005), 637-652.

[12] V. Govedarica, M. Jovanović, On the inequalities of Ky Fan, Wang-Wang and Alzer, J. Math. Anal. Appl., 270 (2002), 709-712.

[13] P. S. Bullen, A Dictionary of Inequalities, Longman, Harlow, 1998.

[14] D. S. Mitrinović, J. E. PeČArić, V. Volenec, Recent Advances in Geometric Inequalities, Kluwer Academic Publishers Group, Dordrecht, 1989. 